\title{
THE 1995 WORLD MICROCOMPUTER CHESS CHAMPIONSHIP
}

\author{
David Levy ${ }^{1}$ \\ London, England
}

The ICCA is pleased to announce that the next World Microcomputer Chess Championship will take place in Paderborn, Germany, from October $8^{\text {th }}$ to $15^{\text {th }}, 1995$. The tournament will be played in the Auditorium Maximum at the University of Paderborn.

We are extremely grateful for the generous sponsorship provided by Sun Microsystems GmbH sponsoring this important event. We would also like to thank Dr. Rainer Feldmann of the University of Paderborn who heads the local organisation of the World Championship. As most of you will already know, Paderborn has long been a centre of computer-chess activity in Germany and is one of the leading centres of excellence in this field in the world.

This announcement is to notify potential participants of the most important rules in force during the tournament.

1. The tournament will be organized in one section, using the Swiss system. 11 rounds will be played. The provisional playing schedule will be as follows:

\begin{tabular}{|c|c|}
\hline Sunday October $8^{\text {th }}$ : & October $12^{\text {th }}:$ \\
\hline $\begin{array}{c}\text { 13:00-14:00 Opening ceremony and } \\
\text { players' meeting }\end{array}$ & 10:00-16:00 Round 6 \\
\hline 14:00-22:00 Round 1 & 16:00-22:00 Round 7 \\
\hline Monday October $9^{\text {th }}: \bullet$ & Friday October $13^{\text {th }}$ : \\
\hline 14:00-22:00 Round 2 & $\begin{array}{l}\text { 10:00-16:00 Round } 8 \\
\text { 16:00-22:00 Round } 9\end{array}$ \\
\hline Tuesday October $10^{\text {th }}:$ & Saturday October $14^{\text {th }}:$ \\
\hline 10:00-16:00 Round 3 & 10:00-16:00 Round 10 \\
\hline 16:00-22:00 Round 4 & Social event or dinner \\
\hline Wednesday October $11^{\text {th }}$ : & Sunday October $15^{\text {th }}$ : \\
\hline 10:00-16:00 Round 5 & $\begin{array}{ll}\text { 10:00-16:00 } & \text { Round } 11 \\
16: 00- & \text { Closing ceremony and } \\
& \text { prizegiving }\end{array}$ \\
\hline
\end{tabular}

The starting times of rounds 4,7 and 9 are subject to change depending on the completion of previous rounds. In any case the tournament hall must be vacant on 22:00 hours every day.

You will note that the schedule has been arranged to allow everyone to arrive in time to set up and test their computers on Saturday October $7^{\text {th }}$, and to travel back on the evening of Sunday October $15^{\text {th }}$. This means that those of you who need to take time off work will only need to take one week, though a full week.

2. The rate of play will be 30 moves in the first hour and 40 moves in each subsequent hour. After 6 hours' elapsed time, the Tournament Director has the right to adjudicate a game using the presumption of perfect play.

1 89, Constantine Road, London, NW3 2LP England. Email: DavidL@intrsrch.demon.co.uk. 
3. All participants are responsible for their own travelling expenses and accommodation. Inexpensive accommodation will be available and details of this will be sent out as soon as possible.

4. We hope to organize an excursion on one of the half days - free of charge to participants.

5. There is no entry fee for amateur entries (defined below).

Commercial entrants other than chess-computer manufacturers must pay an entry fee of US $\$ 1,000$. Chess-computer manufacturers may enter one of their dedicated chess computers and must pay an entry fee of US $\$ 4,000$.

6. The following titles will be awarded at the tournament:

a) Absolute World Microcomputer Chess Champion - for the overall winner of the tournament.

b) World Microcomputer Amateur Chess Champion - for the highest-placed entry by a team made up entirely from amateur programmers (as by rule 13).

c) World Microcomputer Professional Chess Champion - for the highest-placed entry by a non-amateur team.

d) Chess-Computer Manufacturer's World Champion - for the highest-placed entry by a dedicated chess computer.

7. In the event of a tie for any of the titles, a one-game play-off will be organized between the tied programs. If more than two programs are involved in the tie, the play-off game will be between the two programs which have the best tie-break scores. The rate of play for a tie-break game will be decided by the Tournament Director, bearing in mind the time available to play the game. If the play-off game is drawn, then the tie-breaking criterion, as specified by rule 8 , will be used to determine the winner of the title.

8. The first tie-break criterion will be the sum of the opponents' scores. The secondary tie-breaking criterion will be the cumulative total of the respective programs' own scores after round 1, round 2, round $3, \ldots$ round 11 .

9. A speed-chess event will be held on an ad-hoc basis during the World Championship, the winner of which will be awarded the title of World Microcomputer Speed-Chess Champion.

There will be no additional entry fees for commercial and dedicated entries which are already participating in the main event. The number of rounds and the rate of play for this event will be decided by consensus at the start of the World Championship.

10. The chess-playing code of a participating program must execute on a single, generally-available microprocessor. In the case of any doubt, the decision of the ICCA will be made in accordance with the spirit of this rule. A single processor SPARC machine will be allowed.

11. All participating computers must be on site. $90 \mathrm{MHz}$ Pentium computers will be made available free of charge to all participants who request this at least 4 weeks prior to the start of the event. After that date, the ICCA will make every possible effort to help arrange the loan of a suitable computer but this cannot be guaranteed. Any participants who would like the help of the ICCA and the local organisers in arranging the loan of computers other than PCs should advise me as early as possible and we will do everything we can to help, although we cannot guarantee success. Sun Microsystems GmbH has generously offered to loan Sparc computers to all those who need them.

12. The Tournament Director will be David Levy for rounds 1-5 and Professor Jaap van den Herik for rounds 6-11.

13. "Amateur" status - This subject was debated before and during the recent ICCA tournament in Hong Hong. We asked the participants in Hong Kong to suggest a workable definition for the future and 9 of them replied. Unfortunately we have not made very much progress in reaching a satisfactory definition of "amateur" because of the difference of opinion between these 9. For example: 3 of them preferred a definition such as someone who earns absolutely no money from chess programming; 4 of them suggested that the limit should be some part of their income $(10 \%-20 \%$, or $25 \%$, or 900 DM per month, or "not making sufficient money" from the sales), while the other 2 had different suggestions (e.g., not actually selling a program). In Hong Kong the question of amateur status was tied to the 
amount of financial support that a team could receive. In Paderborn this will not arise because there is no financial support for anyone, but we are awarding an Amateur title and we are charging the usual entry fee for commercial programs so the issue is still an important one.

For the purposes of the Paderborn tournament the ICCA will define "Amateur" as someone who is not actively selling a chess program or who can provide written proof (e.g., from a certified accountant) to the Board of the ICCA that their income from such sales is less than $25 \%$ of their total income. In the case of programmers who are selling their programs, this definition puts the onus on the programmer to demonstrate that they deserve to have amateur status.

A list of programs eligible for the Amateur title will be provided to all participants at the start of the event.

\section{ENTRY FORM}

\section{WORLD MICROCOMPUTER CHESS CHAMPIONSHIP}

Author(s) of program':

(Please list the names in the order you wish them to appear in any printed material about the tournament. Note that an entry may be submitted only by one of the authors of a program.)

Name and address for correspondence:

Affiliation (university, company, etc. optional):

Work tel: Home tel:

Fax number: E-mail address:

Name of program:

Estimated rating:

Basis of rating:

\section{INFORMATION ABOUT THE COMPUTER}

Please describe the computer you wish to use. Please indicate if you would like us to try to arrange a computer for your use.

Manufacturer of computer and model:

RAM required:

Disk space:

$\mathrm{O} / \mathrm{S}$ and any additional information:

1 The 1995 ICCA Triennial Meeting has decided that all members of a programming team must be ICCA members of 3 years' standing or must have paid up a 3-year membership. 


\section{INFORMATION ABOUT THE PROGRAM}

Language(s):

Nodes searched per second:

Size of openings book:

Does your program use endgame databases? (If so, please discuss them briefly.)

Who will come to Paderborn to represent and operate your program?

\section{AMATEUR STATUS}

Do you consider your entry to be an amateur entry? If so, please justify your claim.

\section{CLOSING DATE FOR ENTRIES}

We shall endeavour to accept all entries received no later than September $23^{\text {rd }} 1995$. Entries received after that date may be accepted subject to the discretion of the ICCA.

\section{PLEASE SEND ENTRIES TO:}

David Levy, Vice-President ICCA, 89, Constantine Road, London NW3 2LP, England. Tel: +44 171485 9146, fax: +44 171482 0672, Email: DavidL@intrsrch.demon.co.uk.

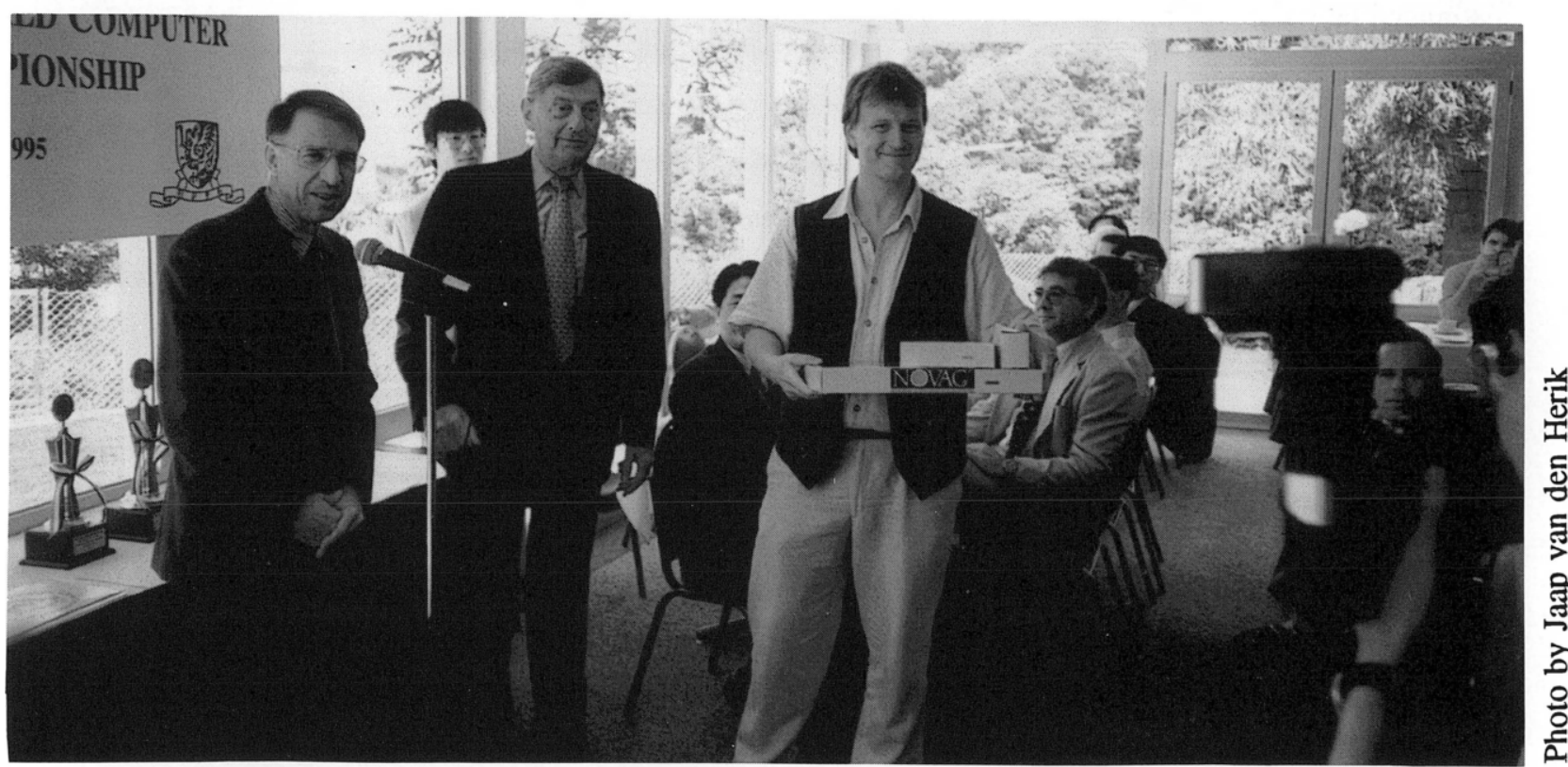

